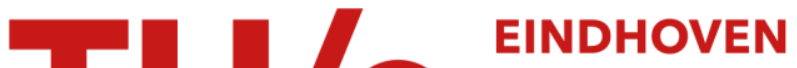

\section{Intrinsic thermal robustness of tunneling spin polarization in Al/Al2O3/Co junctions}

\section{Citation for published version (APA):}

Kant, C. H., Kohlhepp, J. T., Swagten, H. J. M., \& Jonge, de, W. J. M. (2004). Intrinsic thermal robustness of tunneling spin polarization in Al/Al2O3/Co junctions. Applied Physics Letters, 84(7), 1141-1143.

https://doi.org/10.1063/1.1645321

DOI:

10.1063/1.1645321

Document status and date:

Published: 01/01/2004

\section{Document Version:}

Publisher's PDF, also known as Version of Record (includes final page, issue and volume numbers)

\section{Please check the document version of this publication:}

- A submitted manuscript is the version of the article upon submission and before peer-review. There can be important differences between the submitted version and the official published version of record. People interested in the research are advised to contact the author for the final version of the publication, or visit the $\mathrm{DOI}$ to the publisher's website.

- The final author version and the galley proof are versions of the publication after peer review.

- The final published version features the final layout of the paper including the volume, issue and page numbers.

Link to publication

\section{General rights}

Copyright and moral rights for the publications made accessible in the public portal are retained by the authors and/or other copyright owners and it is a condition of accessing publications that users recognise and abide by the legal requirements associated with these rights.

- Users may download and print one copy of any publication from the public portal for the purpose of private study or research.

- You may not further distribute the material or use it for any profit-making activity or commercial gain

- You may freely distribute the URL identifying the publication in the public portal.

If the publication is distributed under the terms of Article 25fa of the Dutch Copyright Act, indicated by the "Taverne" license above, please follow below link for the End User Agreement:

www.tue.nl/taverne

Take down policy

If you believe that this document breaches copyright please contact us at:

openaccess@tue.nl

providing details and we will investigate your claim. 


\title{
Intrinsic thermal robustness of tunneling spin polarization in $\mathrm{Al} / \mathrm{Al}_{2} \mathrm{O}_{3} / \mathrm{Co}$ junctions
}

\author{
C. H. Kant, ${ }^{\text {a) }}$ J. T. Kohlhepp, H. J. M. Swagten, and W. J. M. de Jonge \\ Department of Applied Physics, Center for NanoMaterials and COBRA Research Institute, Eindhoven, \\ University of Technology, P.O. Box 513, 5600 MB Eindhoven, The Netherlands
}

(Received 23 September 2003; accepted 4 December 2003)

\begin{abstract}
Through a direct observation, based on the spin-polarized tunneling technique, we explore the thermal stability of tunneling spin polarization in $\mathrm{Al} / \mathrm{Al}_{2} \mathrm{O}_{3} / \mathrm{Co}$ junctions. Thermal robustness of this parameter, which is of key importance for magnetic tunnel junction performance, is established for in situ postdeposition anneal temperatures up to $500{ }^{\circ} \mathrm{C}$. This stability is consistent with detailed in situ $\mathrm{x}$-ray photoelectron spectroscopy measurements on the $\mathrm{Al}_{2} \mathrm{O}_{3} / \mathrm{Co}$ system which show no structural changes during the anneal. Our results imply that, for comparable magnetic tunnel junction devices, thermal stability is not limited by intrinsic processes in the $\mathrm{Al}_{2} \mathrm{O}_{3}$ barrier and its interfaces. With ex situ postdeposition annealing in an Ar-atmosphere, which leads to severe degradation of the spin polarization above $250^{\circ} \mathrm{C}$, we demonstrate that the spin polarization is extremely vulnerable to diffusion of impurities. (c) 2004 American Institute of Physics.
\end{abstract}

[DOI: $10.1063 / 1.1645321]$

Magnetic tunnel junctions (MTJs) have a high potential for industrial applications ${ }^{1}$ because of their large room temperature tunnel magnetoresistance (TMR) effect. ${ }^{2}$ MTJs are under development to utilize the TMR effect in magnetic random access memories. ${ }^{3}$ Postdeposition annealing of MTJs typically leads to a severe degradation of the TMR effect above $200^{\circ} \mathrm{C}$. Since incorporation of MTJs into existing semiconductor technology requires thermal stability of TMR up to $400{ }^{\circ} \mathrm{C}$, the influence of a postdeposition annealing process is currently under investigation. ${ }^{4-6}$

TMR originates from the tunneling spin polarization determined by the atomic and electronic structure at both barrier/ferromagnetic interfaces. This crucial role of the interface structure has been suggested in several experimental papers, e.g., using dusting layers, ${ }^{7-9}$ alternative barrier/ electrode combinations, ${ }^{10}$ and by theoretical calculations. ${ }^{11,12}$ The tunneling spin polarization from a single barrier/ ferromagnet interface can be measured directly with the spinpolarized tunneling (SPT) technique, ${ }^{13}$ in which the Zeemansplit superconducting density of states in a thin $\mathrm{Al}$ counter electrode is used as a spin detector.

In this article, we present an investigation of the thermal stability of tunneling spin polarization based on SPT. We show that the spin polarization in $\mathrm{Al} / \mathrm{Al}_{2} \mathrm{O}_{3} /$ Co tunnel junctions is stable up to $500^{\circ} \mathrm{C}$. Additionally, with in situ x-ray photoelectron spectroscopy (XPS) measurements we can exclude structural changes of the $\mathrm{Al}_{2} \mathrm{O}_{3} /$ Co system during the postdeposition anneal. These results imply that the thermal stability of TMR in comparable MTJs is not limited by the intrinsic stability of the $\mathrm{Al}_{2} \mathrm{O}_{3}$ barrier and its interfaces. Furthermore, we demonstrate that annealing under high-vacuum conditions is of crucial importance.

Our tunnel junctions are prepared by dc magnetron sputtering (base pressure $<10^{-9}$ mbar) through metal shadow masks on glass substrates at room temperature. The $\mathrm{Al}_{2} \mathrm{O}_{3}$

a)Electronic mail: c.h.kant@tue.nl tunnel barrier is obtained by partially oxidizing a $40 \AA \mathrm{Al}$ bottom electrode with an in situ oxygen plasma $\left(10^{-1}\right.$ mbar, $5 \mathrm{~W})$ for $200 \mathrm{~s}$. The plasma-oxidation is followed by deposition of $200 \AA$ Co top-electrodes in a cross-stripe configuration which are finally capped with $60 \AA \mathrm{Ta}$. The resulting junctions have an area of $400 \mu \mathrm{m} \times 400 \mu \mathrm{m}$ and a resistance-area product of roughly $10^{5} \mathrm{k} \Omega \mu \mathrm{m}^{2}$.

For the spin-polarized tunneling measurements the junctions are cooled to $0.3 \mathrm{~K}$ in a sorption-pumped ${ }^{3} \mathrm{He}$-cryostat. Current-voltage $(I-V)$, and conductance $(d I / d V-V)$ characteristics are measured in a four-terminal configuration using a standard lock-in technique. Our Al bottom electrodes become superconducting at about $2.2 \mathrm{~K}$ and have critical fields of $4.5 \mathrm{~T}$. Figure 1(a) shows a representative conductance measurement in zero field and a field of $3.0 \mathrm{~T}$ performed on a junction which is not annealed. The spin polarization is extracted by fitting the model based on the Maki theory ${ }^{14-16}$ to the conductance curves. This model accounts for the effect of orbital-depairing and spin-orbit scattering on the superconducting density of states. ${ }^{13}$ We find a spin polarization of $39 \pm 1 \%$, with the error margin determined by sample-to-sample variation, which is in fair agreement with earlier work. ${ }^{17,18}$

To investigate the thermal stability of the spin polarization, junctions are postdeposition in situ annealed for $30 \mathrm{~min}$ while the pressure was in the low $10^{-9}$ mbar range. The junctions start to show metallic shorts for anneal temperatures exceeding $500{ }^{\circ} \mathrm{C}$, well above the thermal stability requirement for device implementation. Probably, this is related to thermal stresses in the $\mathrm{Al}_{2} \mathrm{O}_{3}$ barrier, or other processes, which are, however, outside the scope of this article. For temperatures below $500{ }^{\circ} \mathrm{C}$ the junctions are stable without significant changes in the junction resistance. However, this does not exclude delicate structural or chemical changes at the barrier interfaces, which, as mentioned before, are key to the spin polarization. Several thermal processes, possibly affecting the spin polarization, have been proposed. 


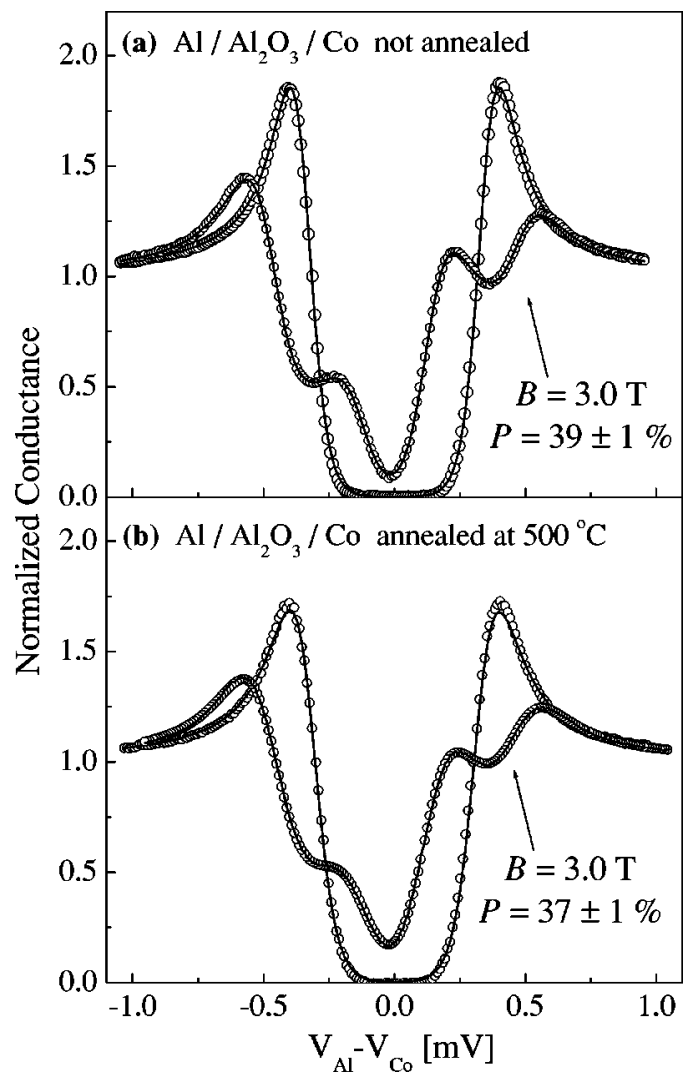

FIG. 1. Conductance measurements of $\mathrm{Al} / \mathrm{Al}_{2} \mathrm{O}_{3} /$ Co junctions at $0.3 \mathrm{~K}$ in zero-field and an applied field of $3 \mathrm{~T}$ performed before (a) and after a $500{ }^{\circ} \mathrm{C}$ in situ postdeposition anneal (b). The solid lines are theoretical fits.

Monsma and Parkin ${ }^{19}$ consider oxidation of the ferromagnet at the interface. Closely related, Sousa et al. ${ }^{20}$ investigated the $\mathrm{Al}_{2} \mathrm{O}_{3}$ barrier in their MTJ structure with Rutherford backscattering and observed a redistribution of oxygen.

To address these issues, we have performed in situ XPS on the $\mathrm{Al}_{2} \mathrm{O}_{3} / \mathrm{Co}$ system before and after a $500^{\circ} \mathrm{C}$ anneal. For careful investigation of the oxidation state of $\mathrm{Co}$ at the interface, the Co thickness in this case is only $5 \AA$. Figure 2(a) shows the XPS intensity in the $\mathrm{Al} 2 s$ and the Co $3 p$ region measured before annealing. Due to the oxidation state of the $\mathrm{Al}$, the $\mathrm{Al}$ lines are chemically shifted with respect to the binding energies measured before the plasma oxidation (indicated by the vertical lines), in accordance with earlier reports which focus on the plasma oxidation of $\mathrm{Al}^{21,22}$ The binding energies of the Co lines coincide with those documented for clean metallic Co. Figure 2(b) shows the spectrum measured after the $500^{\circ} \mathrm{C}$ anneal. The Co lines are still located at their original positions indicating that the $\mathrm{Co}$ is not oxidized during the anneal. We have also verified that the Co $2 p$ lines, which give more XPS signal and are more sensitive to chemical changes, are not affected by the anneal as well. In order to check the sensitivity for oxidation, the Co is oxidized deliberately revealing clear chemical shifts as shown in Fig. 2(c). These results show that $\mathrm{Co}$ at the $\mathrm{Al}_{2} \mathrm{O}_{3} / \mathrm{Co}$ interface in our junctions does not reduce to an oxide either during deposition or a $500^{\circ} \mathrm{C}$ postdeposition anneal.

To investigate the issue of oxygen redistribution, as suggested by Sousa et al., we have monitored XPS spectra of the $\mathrm{O} 1 s$ line. In a careful comparison of normal and grazing Downloaded 14 Nov 2007 to 131.155.108.71. Redistribution subje

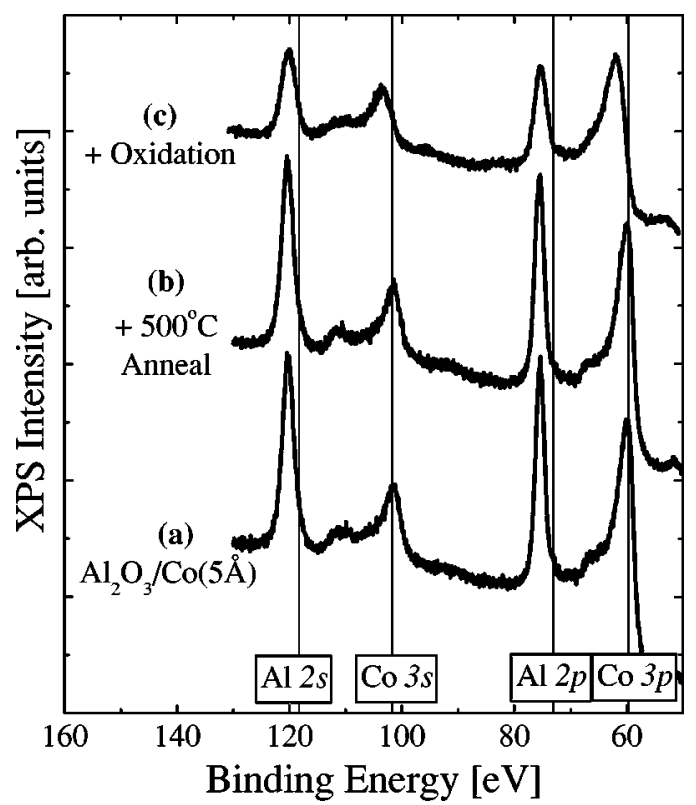

FIG. 2. In situ XPS study on the chemical stability of the $\mathrm{Al}_{2} \mathrm{O}_{3} / \mathrm{Co}$ interface during a $500{ }^{\circ} \mathrm{C}$ anneal. The binding energies of the Co lines measured before the anneal (a), after the anneal (b), and after deliberate oxidation (c), indicate that $\mathrm{Co}$ is not oxidized during the anneal.

emission spectra (which provides depth resolution), measured before and after the anneal, we could not identify oxygen in different chemical environments, significant changes in the $\mathrm{O}-\mathrm{Al}$ ratio or a shift of the $\mathrm{O} 1 s$ binding energy. To gain extra sensitivity for the $\mathrm{O} 1 s$ line, we have repeated the experiment on another sample without the Co layer. Also in this case we could not observe significant changes. Thus, in contrast with the observation of Sousa et al., we do not observe migration of oxygen in our junctions. This discrepancy may be explained by the fact that our barrier is formed by partial oxidation of a single $\mathrm{Al}$ bottom electrode, whereas in the work of Sousa et al. the barrier is formed by oxidation of an $\mathrm{Al}$ film deposited on top of a CoFe bottom electrode.

Figure 1(b) shows representative conductance measurements of a junction which is postdeposition annealed at $500^{\circ} \mathrm{C}$ for $30 \mathrm{~min}$. The spin polarization measured after the anneal is $37 \pm 1 \%$, essentially the same as before the anneal which is consistent with the absence of major structural and chemical changes as reported above. It could be argued that the anneal procedure affects the superconducting properties of the ultrathin $\mathrm{Al}$ electrode by which the obtained spin polarization is no longer accurate. This is, however, not the case. The superconducting transition temperature and the spin-orbit parameter, which is extracted from the conductivity curves measured in a magnetic field, ${ }^{13}$ are not significantly changed. This thermal stability of the Al superconducting electrode implies that the SPT technique is unambiguously applicable. The present results of an intrinsically stable $\mathrm{Al}_{2} \mathrm{O}_{3} /$ Co system can be regarded as a test case and provides a basis for future research. We suggest that meta-stable systems, such as $\mathrm{Al}_{2} \mathrm{O}_{3} / \mathrm{Ni}$ (Ref. 19) or possibly $\mathrm{Al}_{2} \mathrm{O}_{3} / \mathrm{Gd}$, studied with SPT in combination with XPS (and/or ultraviolet photo-electron spectroscopy), provide the opportunity for observing interesting correlations between polarization and barrier/ferromagnet interface structure.

The thermal stability reported here is in sharp contrast

IP license or copyright, see http://apl.aip.org/apl/copyright.jsp 


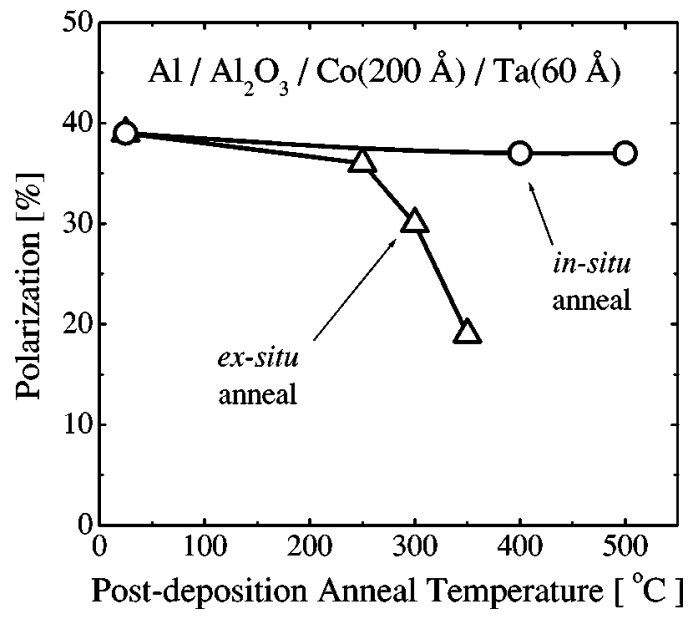

FIG. 3. Spin polarization after in situ and ex situ postdeposition annealing.

with the severe degradation of the TMR effect above $200^{\circ} \mathrm{C}$ observed in comparable MTJ structures (see, for example, Ref. 23). The suggested explanation for this degradation is the diffusion of $\mathrm{Mn}$ atoms from exchange-bias layers to the barrier/ferromagnet interfaces. Our results prove that indeed the stability of TMR in Co-based MTJs is limited by extrinsic processes (e.g., diffusion of Mn atoms) and not by intrinsic processes in the barrier and its interfaces.

To demonstrate the influence of impurity diffusion, we have annealed the same $\mathrm{Al} / \mathrm{Al}_{2} \mathrm{O}_{3} / \mathrm{Co}$ junctions ex situ in an Ar-atmosphere instead of a high-vacuum chamber. Despite the fact that the Co electrode is capped with $60 \AA \mathrm{Ta}$, impurities present in the Ar-atmosphere diffuse into the junction structure, which is, probably, occurring predominantly along grain boundaries. As in the case of the high-vacuum anneal, both the junction resistance and superconducting properties of the $\mathrm{Al}$ electrode remain unchanged. However, as shown in Fig. 3, the spin polarization starts to degrade severely above $250{ }^{\circ} \mathrm{C}$, reminiscent of the degradation of TMR. ${ }^{23}$ The degradation can be explained by contamination of the barrier/ ferromagnet interface by foreign atoms, ${ }^{7-9}$ or by local oxidation of the ferromagnet as considered by Monsma and Parkin, ${ }^{19}$ and earlier in this article. This direct comparison between the high-vacuum and the Ar-atmosphere anneal confirms that the polarization is vulnerable to diffusion of impu- rities. Extended anneal studies, based on SPT and Co electrodes containing well-defined impurity layers, further establishing these diffusion processes, will be the topic of future publications.

In summary, we have shown that the tunneling spin polarization in $\mathrm{Al} / \mathrm{Al}_{2} \mathrm{O}_{3} / \mathrm{Co}$ junctions is intrinsically stable up to $500^{\circ} \mathrm{C}$. Ex situ postdeposition annealing in an Aratmosphere demonstrates that the polarization is extremely vulnerable to diffusion of impurities.

${ }^{1}$ G. A. Prinz, Science 282, 1660 (1998).

${ }^{2}$ J. S. Moodera, L. R. Kinder, T. M. Wong, and R. Meservey, Phys. Rev. Lett. 74, 3273 (1995).

${ }^{3}$ S. Tehrani, J. M. Slaughter, M. Deherrera, B. N. Engel, N. D. Rizzo, J. Salter, M. Durlam, R. W. Dave, J. Janesky, B. Butcher, K. Smith, and G. Grynkewich, Proc. IEEE 91, 703 (2003).

${ }^{4}$ S. Cardoso, P. P. Freitas, Z. G. Zhang, P. Wei, N. Barradas, and J. C. Soares, J. Appl. Phys. 89, 6650 (2001).

${ }^{5}$ M. T. Lin, C. H. Ho, Y. D. Yao, R. T. Huang, C. C. Liao, F. R. Chen, and J. J. Kai, J. Appl. Phys. 91, 7475 (2002).

${ }^{6}$ C. S. Yoon, J. H. Lee, D. Jeong, C. K. Kim, J. H. Yuh, and R. Haasch, Appl. Phys. Lett. 80, 3976 (2002).

${ }^{7}$ P. LeClair, H. J. M. Swagten, J. T. Kohlhepp, R. J. M. van de Veerdonk, and W. J. M. de Jonge, Phys. Rev. Lett. 84, 2933 (2000).

${ }^{8}$ P. LeClair, B. Hoex, H. Wieldraaijer, J. T. Kohlhepp, H. J. M. Swagten, and W. J. M. de Jonge, Phys. Rev. B 64, 100406 (2001).

${ }^{9}$ P. LeClair, J. T. Kohlhepp, H. J. M. Swagten, and W. J. M. de Jonge, Phys. Rev. Lett. 86, 1066 (2001).

${ }^{10}$ J. M. D. Teresa, A. Barthélémy, A. Fert, J. P. Contour, F. Montaigne, and P. Seneor, Science 286, 507 (1999).

${ }^{11}$ P. K. de Boer, G. A. de Wijs, and R. A. de Groot, Phys. Rev. B 58, 15422 (1998).

${ }^{12}$ I. I. Oleinik, E. Y. Tsymbal, and D. G. Pettifor, Phys. Rev. B 65, 020401 (2001).

${ }^{13}$ R. Meservey and P. M. Tedrow, Phys. Rep. 238, 173 (1994).

${ }^{14}$ K. Maki, Prog. Theor. Phys. 32, 29 (1964).

${ }^{15}$ R. Meservey, P. M. Tedrow, and R. C. Bruno, Phys. Rev. B 11, 4224 (1975).

${ }^{16}$ D. C. Worledge and T. H. Geballe, Phys. Rev. B 62, 447 (2000).

${ }^{17}$ J. S. Moodera, J. Nassar, and G. Mathon, Annu. Rev. Mater. Sci. 29, 381 (1999).

${ }^{18}$ D. J. Monsma and S. S. P. Parkin, Appl. Phys. Lett. 77, 720 (2000).

${ }^{19}$ D. J. Monsma and S. S. P. Parkin, Appl. Phys. Lett. 77, 883 (2000).

${ }^{20}$ R. C. Sousa, J. J. Sun, V. Soares, and P. P. Freitas, Appl. Phys. Lett. 73, 3288 (1998).

${ }^{21}$ P. LeClair, J. T. Kohlhepp, A. A. Smits, H. J. M. Swagten, B. Koopmans, and W. J. M. de Jonge, J. Appl. Phys. 87, 6070 (2000).

${ }^{22}$ K. Knechten, P. LeClair, J. T. Kohlhepp, H. J. M. Swagten, B. Koopmans, and W. J. M. de Jonge, J. Appl. Phys. 90, 1675 (2001).

${ }^{23}$ S. Cardoso, P. P. Freitas, C. de Jesus, P. Wei, and J. C. Soares, Appl. Phys. Lett. 76, 610 (2000). 